\title{
Can affective domain skills be developed in nursing education?
}

\section{Hemşirelik eğitiminde duyuşsal alan becerileri geliştirilebiliyor mu?}

\author{
Fatma Nevin ŞişMAN ${ }^{1}$, Sevim BUZLU
}

\section{ABSTRACT}

When providing care, it is very important for the nurse to understand the patient, to manage his/her emotions, to empathize, and communicate with the patient effectively. In order to achieve this, nurses primarily need to aware of, express, and manage their own feelings and develop skills of empathy. Because the use of these developed skills in occupational practices would increase the quality of care, it is important to make these skills gained during training period. In this review, affective domain skills of nursing students in their undergraduate education were reviewed in the light of current literature.

Key words: Nursing, nursing students, emotion, affective domain, care

\section{Öz}

\begin{abstract}
Hemşirenin bakım hizmeti verirken hastayı anlayabilmesi, onun duygularını yönetebilmesi için etkili iletişim kurması ve empati yapabilmesi çok önemlidir. Bunu yapabilmesi için hemşirelerin kendi duygularını fark etmesi, dile getirmesi, yönetmesi ve empati becerilerini geliştirmesi gerekmektedir. Bu becerilerin mesleki uygulamalarda kullanımı bakımın kalitesini artıracağından eğjtim sürecinde kazandırılması önem kazanmaktadır. Bu derlemede, hemşirelik öğrencilerinin lisans eğitimlerinde duyuşsal becerileri düzeyleri güncel literatür ışığında gözden geçirilmiştir.
\end{abstract}

Anahtar kelimeler: Hemşirelik, hemşirelik öğrencileri, duygu, duyuşsal alan, bakım

\section{Giriş}

Duygu, fizyolojik ve bedensel bir yaşantı veya bir hisle ilişkili farkındalık ve diğerlerince gözlenebilen davranışlarda sergilenen ifadeler olarak tanımlanmaktadır ${ }^{1}$. Mayer, Salovey ve Caruso (2000)'ya göre duygunun tanımı, bireyin ilişkilerinde gösterdiği dört bileşenden oluşan fizyolojik, deneyimsel ve bilişsel tepkilerdir. illk bileşende duyguların farkına varma, bedeni kullanarak ve ses tonu ile gösterme, ikinci bileşende duyguları tanımlayabilme, üçüncü bileşende duyguları deneyimleme yeneteği ve son bileşende ise duyguları düzenleme yeteneği yer alır². Fridja (1996) duygu oluşum sürecinde ilk olarak bireyde bir olaya karşı tepki oluştuğunu, oluşan tepkinin niteliğinin, bireyin sahip olduğu mizaç ve eğilimlerinin etkisi altında şekillenip duyguyu oluşturduğunu ve oluşan duygunun da davranışın oluşmasına neden olduğunu ifade belirtmiştir ${ }^{3}$. Ayrıca; duygunun ortaya çıkmasının, bireyin geçmişine ve kişilik özelliklerine göre şekil aldığını söylemek olasıdır.

Duygu ortaya çıktıktan sonra bunun fark edilmesi ve uygun bir şekilde gösterilmesi önem kazanmaktadır. Kişi, ancak kendi duygularını tam olarak algıladığında ve yönettiğinde ilişkilerinde başarılı olabilir ${ }^{5}$.

Kişinin duygularını anlaması, başkalarına empati duyması ve duygularını düzenleyebilme yetisi Daniel Goleman tarafından duygusal zeka (DZ) olarak tanımlanmaktadır. Bu tanıma göre kişinin duygularının farkında olması, duyguları gösterme, duygularını yöne- 
tebilmesi, diğer kişilerle empati yapabilme becerisi duygusal zekanın bileşenlerini oluşturmaktadır ${ }^{6}$.

Sağlıklı bir şekilde duygularının farkında olan ve gösterebilen bireylerde empati yeteneği de gelişmiş olur. Empati, duygusal olarak kendini başkalarının yerine koyabilme kapasitesini gösterdiği için öncelikle kişinin kendi duygularını tanımasını gerektirmektedir,8.

\section{Hemşirelikte Duyuşsal Alanın Önemi}

Hemşirelik mesleği insan insana ilişkiyi temel alır ve hemşirelik mesleğinde hemşire, temel sorumluluğu olan bakım görevini, sağlıklı/hasta bireylerle kurduğu ilişki ile yapabilir ve bu ilişki, bakımın temelini oluşturur. Hemşire kuramcılardan Peplau ve Orlando, sağlıklı/hasta bireylerin gereksinimlerini her zaman açıkça dile getiremediklerini, hemşirenin bu gereksinimleri belirleyebilmesi için iyi düzeyde kişilerarası ilişki becerilerine sahip olması gerektiğine vurgu yapmaktadırlar9. Kişiler arası ilişkilerde başarılı olabilmek için ise duyuşsal alan becerilerinin kullanılması gerekmektedir.

Bireyin başkalarının duygularını anlamasının en iyi yolunun, kendi duygularına karşı geliştirmiş olduğu farkındalıktan geçtiği belirtilmektedir ${ }^{10}$. Duygularının farkında olan kişilerin, duygularını kontrol edebildiği, yönetebildiği ve bu duyguları kullanarak zorlu durumlara daha iyi uyum sağlayabildikleri, sorunlarını daha kolay çözümleyebildikleri ayrıca başkalarının duygularını da daha rahat anlayabildikleri belirtilmekte$\mathrm{dir}^{11}$. Duygularını tanıyan, yöneten, empati yapabilen, ilişkilerini yönlendirebilen, kendisini gerçekleştiren hemşirelerin hem kendi ruh sağığını koruyabildiği hem de sağlıkı/hasta bireylere bakımda bulunurken, bu yeteneklerini kullanıp bakımın kalitesini arttırdığı dile getirilmekte ve bu sayede toplumun ruh sağlığını da korumaya katkı sağladıkları belirtilmektedir ${ }^{12,13}$.

\section{Hemşirelikte Duyuşsal Alan Becerilerinin Kullanımı}

Hemşirelerin empati yapabilmesi, hasta/sağlıklı bireyi tam anlamıyla anlayıp, gereksinimlerini belirlemesi ve bu gereksinimlerin giderilmesinde yardım edebilmesi önemli bir gösterge olarak değerlendirilmektedir ${ }^{7,14,15}$. Yapılan araştırmalarda, hemşirenin bireyi önemli ve değerli görüp kabullenmesi, saygı göstermesi ve empatik yaklaşımda bulunmasının, bireyin hemşireye güven duymasını sağladığı, bu sayede bakım için gerekli olan terapötik ortamın sağlanmış olduğu belirtilmektedir ${ }^{16,17}$. Hastadaki olumlu gelişmelerin de, hemşirelerde mesleki doyum sağladığı vurgulanmaktadır ${ }^{18,19}$. Ayrıca, hemşirelik mesleğinin, hastalarla doğrudan birebir etkileşimde bulunmayı gerektirmesi ve sağlık bakımının ekip ile iş birliği içerisinde sunulması, duyguları yönetme becerisini etkin bir şekilde kullanılmasını gerektirmektedir ${ }^{20}$.

Gelişmiş duygusal zeka becerisine sahip hemşirelerin karşılaştığı stresli durumların üstesinden gelip, sorunları zorlanmadan çözümledikleri ${ }^{21-23}$ ve yeterlilik duygusu ile kendini başarılı hissedip iş doyumlarının arttığı belirtilmektedir ${ }^{23,25}$.

Bunların dışında duygusal zeka kavramı üzerine yapılan sistematik incelemelerde, duygusal zeka bileşenlerinden duyguları tanıma, fark etme ve empati yapma becerilerinin hemşirelik uygulamalarının merkezinde olduğu ve duygusal zeka düzeyinin etik karar verme, eleştirel düşünme, araştırma bulguları ve kanıtların uygulamada kullanımı, bakımın kalitesi ve hasta çıktılarını etkilediğ $\mathrm{i}^{26}$ ayrıca, hemşirelerde liderlik, kritik bakım, eğitim/iş birliği, planlama/değerlendirme, kişiler arası ilişkiler, iletişim ve profesyonel gelişim gibi hemşirelik becerilerinin duygusal zeka düzeyi ile ilişkili olduğu belirtilmektedir ${ }^{20,27-30}$.

\section{Hemşirelik Öğrencilerinde Duyuşsal Alan Beceri Düzeyleri}

Duyuşsal alan becerileri farklı kuram ve teorileri temel alarak geliştirilen çeşitli ölçeklerle ölçülebilmektedir ve bu becerilerin düzeyleri, ölçek toplam puan ortalamalarına göre yeterli/yetersiz, düşük/orta/ yüksek gibi derecelendirilebilmektedir. Hemşirelik öğrencilerinin duygusal farkındalık düzeylerini inceleyen çalışmalarda duyguları fark etme becerilerinin yetersiz olduğu ${ }^{31-33}$; duyguların gösterilmesine yönelik yapılan çalışma bulgularına göre de öğrencilerin 
duygularını yeterince gösteremediği belirtilmiştir ${ }^{22,34}$. Ayrıca, literatürde hemşirelik öğrencilerinin empati becerilerinin düşük ya da orta düzeyde olduğu ifade edilmektedir ${ }^{14,17,31,35-40}$. Duygusal zeka düzeyleri incelendiğinde ise, genel olarak düşük ya da orta düzeyde duygusal zekaya sahip oldukları belirtilmiştir ${ }^{30-32,34,41-}$ ${ }^{44}$. Bu bulgular doğrultusunda, duygusal zeka düzeyi, duygusal farkındalık, duyguları gösterme ve empati becerilerinin hemşirelik öğrencilerinde geliştirilmesi gereken beceriler olduğu görülmektedir.

\section{Hemşirelik Eğitiminde Duyuşsal Alanı Geliştirmeye Yönelik Çalışmalar}

Hemşirelik eğitimi alan lisans öğrencilerinin eğitimleri sırasında duyuşsal alan becerilerinin geliştirilmesi için hemşirelik eğitim programlarında yeni düzenlemelerin yapılmasının gerekli olduğu görülmektedir ${ }^{41}$.

Literatürde eğitimleri sırasında öğrencilere, kendi duygularını fark etmeleri, duygularını kontrol etme ve duygusal tepkilerini anlamlandırma becerilerinin kazandırılması için destek olunması gerektiği, öğrencilerin bu alandaki becerilerini hasta bakımında kullanmaları konusunda yönlendirilmesi ve bu konudaki eğitimlerine daha fazla önem verilmesi gerektiği belirtilmektedir22.

Literatür incelendiğinde lisans eğitiminin duyuşsal alan becerilerini geliştirmeye etkisini inceleyen çalışmalar çok kısıtlı olmakla birlikte yalnızca empati becerisindeki gelişimi inceledikleri belirlendi. Duyguları ifade etme, fark etme gibi diğer beceriler üzerine etkisinin incelenmediği görüldü.

Hemşirelikte lisans eğitiminin empatik beceri üzerine etkisinin incelendiği çalışmalarda ise, sınıflar arasında empatik beceri puan ortalaması yönünden istatistiksel olarak anlamlı farklılık olmaması, yürütülen lisans eğitim programının öğrencilerin empatik beceri düzeylerinin gelişmesine fazla katkı sağlamadığı yönünde değerlendirilmiş ders içerikleri ve yöntemlerinin yeniden gözden geçirilmesi gerektiği belirtilmiştir ${ }^{35}$. Bunun tersine farklı eğitim programlarıly lisans eğitimi alan hemşirelik öğrencilerinin eğitim yılı arttıkça empatik beceri puanlarının arttığına dikkat çeken çalışmalar da bulunmaktadır ${ }^{17,45,46}$. Bir başka çalışmada, ise empatik eğilimin birinci sınıflarda, empatik becerinin ise dördüncü sınıflarda daha yüksek olduğu, sınıflar arttıkça empatik beceride artış, empatik eğilimde azalma olduğu belirtilmektedir ${ }^{47}$. Bu verilerden yola çıkarak yapılan çalışmaların lisans eğitimi ile empati becerisinin geliştirilebileceğini gösterdiğini söylemek olasıdır.

Bunun dışında yapılan bir çalışmada ise, hemşirelik öğrencilerinin lisans eğitimleri sırasında aldıkları "Ruh Sağlığı ve Hastalıkları Hemşireliği" dersinin de öğrencilerinin duygusal durumlara yaklaşma becerisini geliştirme üzerinde etkili olduğu gösterilmektedir ${ }^{48}$. Hemşirelik lisans eğitimi sırasında verilen "Kendini Tanıma ve Girişkenlik" dersinin ise duyguları kolaylıkla gösterebilme özelliğini de içinde barındıran atılganlık beceri düzeylerini geliştirdiği belirtilmektedir ${ }^{49}$. "Ruh Sağlığı ve Hastalıkları Hemşireliği" eğitimi ve uygulamaları ile "Kendini Tanıma ve Girişkenlik" dersleri ile öğrencilerin hastaların duygularına yaklaşabilmeleri, ele alabilmeleri ve duygulardan kaçınmayı etkileyen faktörleri tanıyabilme ve duygularını kolaylıkla gösterebilme becerilerini kazanmalarının sağlanmakta olduğu görülmektedir.

\section{SONUÇ}

Öğrencilerde bilişsel, duyuşsal ve davranışsal alanları geliştirmeye yönelik verilen hemşirelik eğitiminin duyguları fark etme ve tanımlamaya yönelik tutum geliştirmede yeterince etkili olup olmadığı bilinmemektedir. Çalışmalar ağırlıklı olarak lisans eğitimi ile empati becerisinin geliştirilebilir olduğunu göstermektedir. Az sayıda çalışmada da duygulara yaklaşabilme ve duyguları gösterme becerilerinin geliştirilebildiği belirtilmiştir. Duyguları fark etme gibi diğer duyuşsal alan değişkenlerini geliştirmeye yönelik hemşirelik öğrencilerinde yapılan herhangi bir çalışmaya rastlanmamıştır. Bu anlamda çalışmalar yetersiz kalmaktadır. Empati dışındaki duyuşsal alan becerilerini geliştirmede etkinliği test eden çalışmaların yapılması gerekmektedir. 
Duyguları temel alan eğitim programlarının geliştirilip etkinliğinin test edildiği çalışmaların yapılması ve çalışma sonuçlarının hemşirelik eğitimine uyarlanması sağlanabilir. Duygularını tanımlama ve empati becerisi gelişmiş olarak mezun olan hemşirelerin bu becerilerini davranışa dönüşmesi ve mesleki yaşamda kullanması ile hemşirelik bakımında, kişiler arası ilişkilerde ve ekip çalışmasında daha verimli ve doyumlu çalışmalarını sağlayacak ve böylece mesleklerinde başarılı olabileceklerdir.

\section{KAYNAKLAR}

1. Morgan CT. Psikolojiye Giriş. Karakaş S, Eski R (çev). 18. baskı. İstanbul, Eğitim Akademi Kitabevi Yayınları, 2009:194-234.

2. Mayer J, Salovey P, Caruso D. Models of Emotional Intelligence. Handbook of Intelligence. New York, Cambridge University Press, 2000: 396-420.

3. Frijda NH. Passions: Emotion and socially consequential behaviour. In: Emotion: Interdisciplinary Perspectives. Kavanaugh RD, Zimmer-Berg B, Fein S (eds). Mahraw, New Jersey, Lawrence Erlbaum Associates Publishers, 1996:1-27.

4. Kagan J. What Is Emotion: History, Measures, and Meanings. Yale University Press, 2007:1.

5. Akerjordet K, Severinsson E. Emotional intelligence: A review of the literature with specific focus on empirical and epistemological perspectives. Journal of Clinical Nursing 2007; 16(8):1405-16. http://dx.doi.org/10.1111/j.1365-2702.2006.01749.x

6. Goleman D. Duygusal Zeka. 32. baskı. İstanbul, Varlık YayınlarI, 2009: 67.

7. Mercer SW, Reynolds WJ. Empathy and quality of care. British Journal of General Practice 2002;52:9-13.

8. Pala A. Öğretmen adaylarının empati kurma düzeyleri üzerine bir araştırma. Pamukkale Üniversitesi Eğitim Fakültesi Dergisi 2008;23(1):13-23.

9. Freshwater D, Stickley T. The heart of the art: Emotional intelligence in nurse education. Nursing Inquiry 2004;11(2):91-8. http://dx.doi.org/10.1111/j.1440-1800.2004.00198.x

10. Tarhan N. Duyguların Dili. 6. baskı. İstanbul, Timaş Yayınları, 2009:75.

11. Hisli Sahin N, Güler M, Basim HN. The relationship between cognitive intelligence, emotional intelligence, coping and stress symptoms in the context of type A personality pattern. Türk Psikiyatri Derg 2009;20:243-54.

12. Bellack JP. Emotional intelligence: A missing ingredient? Journal of Nursing Education 1999;38(1):3-4.

13. Akerjordet $K$, Severinsson E. Emotional intelligence in mental health nurses talking about practice. Int J Ment Health Nurs 2004;13:164-70. http://dx.doi.org/10.1111/j.1440-0979.2004.0328.x

14. Nunes P, Williams S, Sa B, Stevenson K. A study of empathy decline in students from five health disciplines during their first year of training. International Journal of Medical Education 2011;2:12-7. http://dx.doi.org/10.5116/ijme.4d47.ddb0

15. Ward J, Cody J, Schaal M, Hojat M. The empathy enigma: An empiricalstudy of decline in empathy among under gradu- ate nursing students. Journal of Professional Nursing 2012; 28(1):34-40.

http://dx.doi.org/10.1016/j.profnurs.2011.10.007

16. Mete $S$, Gerçek E. PDÖ yöntemiyle egitim gören hemşirelik ögrencilerinin empatik eğilim ve becerilerinin incelenmesi. Cumhuriyet Üniversitesi Hemsirelik Yüksek Okulu Dergisi 2005;9(2):11-7.

17. Cevahir R, Çınar N, Sözeri C, Sahin S, Kuguoglu S. Ebelik öğrencilerinin devam ettikleri sınıflara göre empatik becerilerinin degerlendirilmesi. Fırat Saglık Hizmetleri Dergisi 2008;3(7):5-13.

18. Maatta SM. Rethinking empathy in nursing education: Shifting to a developmental view. Nursing Philosophy 2006;7(1):3-10. http://dx.doi.org/10.1111/j.1466-769X.2006.00232.x

19. Williams J, Stickley T. Empathy and nurse education. Nurse Education Today 2010;30(8):752-5. http://dx.doi.org/10.1016/j.nedt.2010.01.018

20. McQueen AC. Emotional intelligence in nursing work. J Adv Nurs 2004;47(1):101-8. http://dx.doi.org/10.1111/j.1365-2648.2004.03069.x

21. Augusto Landa JM, Lopez-Zafra E, Berrios Martos MP, Aguilar-Luzon Mdel $C$. The relationship between emotional intelligence, occupational stres and health in nurses: A questionnaire survey. International Journal of Nursing Studies 2008;45(6):888-901. http://dx.doi.org/10.1016/j.ijnurstu.2007.03.005

22. Karabulutlu EY, Yılmaz S, Yurttaş A. Öğrencilerin duygusal zekâ düzeyleri ile problem çözme becerileri arasındaki ilişki. Psikiyatri Hemşireliği Dergisi 2011;2(2):75-9.

23. Por J, Barriball L, Fitzpatrick J, Roberts J. Emotional intelligence: Its relationship to stress, coping, well-being and Professional performance in nursing students. Nurse Education Today 2011;31:855-60. http://dx.doi.org/10.1016/j.nedt.2010.12.023

24. Cadman C, Brewer J. Emotional intelligence: a vital prerequisite for recruitment in nursing. J Nurs Manag 2001;9:321-4. http://dx.doi.org/10.1046/j.0966-0429.2001.00261.x

25. Simpson RL, Keegan AJ. How connected are you? Employing emotional intelligence in a high-tech world. Nursing Administration Quaterly 2002;26:80-6. http://dx.doi.org/10.1097/00006216-200201000-00009

26. Smith KB, Profetto-McGrath J, Cummings GG. Emotional intelligence and nursing: An integrative literature review. International Journal of Nursing Studies 2009;46:1624-36. http://dx.doi.org/10.1016/j.ijnurstu.2009.05.024

27. Moyer BA, Wittmann-Price RA. Nursing Education: Foundation for Practice Excellence. Philadelphia, F.A. Davis Company, 2008.

28. Codier E, Kooker BM, Shoultz J. Measuring the emotional intelligence of clinical staff nurses: An approach for improving the clinical care environment. Nursing Administration Quarterly 2008;32(1):8-14. http://dx.doi.org/10.1097/01.NAQ.0000305942.38816.3b

29. Mayer JD, Salovey P, Caruso D. Emotional intelligence: New ability or eclectic traits? The American Psychologist 2008;63(6):503-17. http://dx.doi.org/10.1037/0003-066X.63.6.503

30. Beauvais AM, Brady N, O'Shea ER, Quinn Griffin MT. Emotional intelligence and nursing performance among nursing students. Nurse Education Today 2011;31(4):396-401. http://dx.doi.org/10.1016/j.nedt.2010.07.013

31. Duman D, Acaroğlu R. Hemşirelik yüksekokulu birinci sınıf öğrencilerinin duygusal zekâ düzeyleri ile empati becerileri arasındaki ilişki. Florence Nightingale Hemşirelik Dergisi 
2014;(22)1:25-32.

32. Kuzu A, Eker F. Hemşirelik öğrencilerinin duygusal zeka ve iletişim becerilerinin diğer üniversite öğrencileri ile karşılaştırılmalı olarak değerlendirilmesi. Hemşirelikte Araştırma Geliştirme Dergisi 2010;3:14-29.

33. Ünsar S, Fındık ÜY, Sadırlı Kurt S, Ünsar S. Edirne Sağlık Yüksekokulu öğrencilerinin duygusal zeka düzeyleri. Üniversite ve Toplum Dergisi 2009;9(1):13-27.

34. Tambağ $H$, Kaykunoğlu $M$, Gündüz $Z$, Demir Y. Hemşirelik öğrencilerinin duygusal zeka düzeyleri ve etkileyen faktörler. Hemşirelikte Eğitim ve Araştırma Dergisi 2014;11(1):41-6.

35. Akıncı AÇ, Akgün G. Kırklareli Üniversitesi Sağlık Yüksekokulu hemşirelik öğrencilerinin empatik eğilim ve becerileri. Fırat Sağlık Hizmetleri Dergisi 2011;6(17):53-65.

36. Arifoğlu B, Razı GS. Birinci sınıf hemşirelik öğrencilerinin empati ve iletişim becerileriyle iletişim yönetimi dersi akademik başarı puanı arasındaki ilişki. Dokuz Eylül Üniversitesi Hemşirelik Yüksekokulu Dergisi 2011;4:7-11.

37. Nazik E, Arslan S. Hemşirelik öğrencilerinin empatik becerileri ile öz duyarlıkları arasındaki ilişkinin incelenmesi. Anadolu Hemşirelik ve Sağlık Bilimleri Dergisi 2011;14(4):69-75.

38. Özcan H. Hemşirelerin empatik eğilim ve empatik becerileri: Gümüşhane örneği. Gümüşhane Üniversitesi Sağlık Bilimleri Dergisi 2012;1(2):60-8.

39. Mert H, Sezgin D. Geleneksel ve probleme dayalı ögrenim modeliyle ögrenim gören hemsirelik ögrencilerinin empatik beceri düzeylerinin incelenmesi. Anadolu Hemsirelik ve Saglık Bilimleri Dergisi 2011;14(1):9-13.

40. Karaca A, Açıkgöz F, Akkuş D. Eğitim ile empatik beceri ve empatik eğilim geliştirilebir mi?: Bir sağlık yüksekokulu örneği. Acıbadem Üniversitesi Sağlık Bilimleri Dergisi 2013;4(3):118122.
41. Sevindik F, Uncu F, Dağ DG. Sağlık yüksekokulu öğrencilerinin duygusal zekâ düzeylerinin bazı değişkenler açısından incelenmesi. Fırat Üniversitesi Sağlık Bilimleri Tıp Dergisi 2012;26(1):21-6.

42. Avşar G, Kaşıkçı M. Hemşirelik yüksekokulu öğrencilerinde duygusal zekâ düzeyi. Anadolu Hemşirelik ve Sağıık Bilimleri Dergisi 2010;13(1):1-6.

43. Erdoğdu YM. Duygusal zekanın bazı değişkenler açısından incelenmesi. Elektronik Sosyal Bilimler Dergisi 2008;23:62-76.

44. Yılmaz E, Özkan S. Hemşirelik öğrencilerinin duygusal zekâ düzeylerinin bazı değişkenler açısından incelenmesi. Maltepe Üniversitesi Hemşirelik Bilim ve Sanatı Dergisi 2011;4(1): 39-52.

45. Özyazıcıoğlu N, Aydınoğlu N, Aytekin G. Sağlık yüksekokulu öğrencilerinin empatik ve problem çözme becerilerinin incelenmesi. Atatürk Üniversitesi Hemşirelik Yüksekokulu Dergisi 2009;12(3):46-53.

46. Sabancıoğulları S, Kelleci M, Doğan S, Gölbaşı Z. Entegre eğitim programında öğrenim gören hemşirelik öğrencilerinin empatik eğilim düzeylerinin yıllara göre incelenmesi. Cumhuriyet Üniversitesi Hemşirelik Yüksekokulu Dergisi 2007;11(2):1-7.

47. Özcan CT, Oflaz F, Sütçü Çiçek H. Empathy: the effects of undergraduate nursing education in Turkey. International Nursing Review 2010;57:493-499. http://dx.doi.org/10.1111/j.1466-7657.2010.00832.x

48. Dil S, Aykanat B. Ruh Sağlığı ve Hastalıkları Hemşireliği dersinin hemşirelik öğrencilerinin duygusal durumlara yaklaşma ve kaçınma motivasyon düzeylerine etkisi. Psikiyatri Hemşireliği Dergisi 2013;4(3):125-30.

49. Kelleci M, Avcı D, Emine Ata E, Doğan S. Kendini tanıma ve girişkenlik dersinin hemşirelik öğrencilerinin atılganlık düzeylerine etkisi. Anadolu Hemşirelik ve Sağlık Bilimleri Dergisi 2011;14:46-51. 